\title{
Selective logging causes the decline of large-sized mammals including those in unlogged patches surrounded by logged and agricultural areas
}

\begin{abstract}
Legal and illegal logging is prevalent throughout the tropics, impacting on natural habitat and wildlife. This study aimed to investigate the sensitivity of forest mammals to selective logging in the lowland dipterocarp forests of South-West Peninsular Malaysia and identify the underlying factors that determine species occurrence. A total of 120 camera trap locations were deployed within selectively logged and unlogged forests. We found that unlogged forest had greater wildlife occurrences compared to selectively logged forests, including two endangered mammal species not found in logged forest. Forest vegetation structure characteristics such as the abundance of lianas, large trees, saplings, palms, bamboo and seedlings were associated with mammal species richness. Mammal species richness increased with number of forest trees, particularly those with a DBH of $>45 \mathrm{~cm}$, but this was limited to high altitude forest. Worryingly, we did not detect any large mammalian apex predators such as leopards or tigers in either unlogged or selectively logged forests. The absence of these animals may be the result of poaching, habitat degradation or other pressures; these mammals are expected to be present in intact forests in Peninsular Malaysia. Restoring logged forests and preserving the remaining unlogged lowland dipterocarp forests are critically important to safeguard mammalian biodiversity in the region. Besides that, we recommend that conventional logging practices are replaced with reduced impact logging methods.
\end{abstract}

Keyword: Biodiversity; Camera trap; Deforestation; Peninsular Malaysia; Species richness; Reduced impact logging 